\title{
Effects of Metallic Ions on Nonphotochemical Decay of Pfr in Avena Coleoptiles
}

\author{
Katsushi Manabe and Masaki Furuya \\ Biological Institute, Faculty of Science, Nagoya University, Chikusa, Nagoya 464; \\ Depxrtment of Botxny, Fxculty of Science, University of Tokys, Hongs, Tokyo 113
}

\begin{abstract}
In segments of etiolated Avena coleoptiles, the dark process of Pfr decay was prevented by several metal-complexing and sulfhydryl compounds, and this inhibition was partly recovered when such metallic ions as ferrous, ferric or zinc ion were given to the tissues. Ferric ion recovered the EDTA- and $\alpha, \alpha^{\prime}$-dipyridyl-induced inhibition, but had less effect on the 2-mercaptoethanol-induced one. In contrast, zine ion recovered the latter as well as the former. The inhibition of dark Pfr decay also occurred in the presence of respiratory inhibitors such as azide, antimycin A and rotenone. The azide-induced inhibition was not recovered by the addition of ferric or zinc ions. Thus, the dark Pfr decay appeared to be controlled at, at least, three different processes in this tissue.
\end{abstract}

Far-red absorbing form of phytochrome, Pfr, has been well known to gradually lose its photoreversibility in the dark at room temperature, while maintaining a constant peak ratio of $\triangle \mathrm{Afr} / \Delta \mathrm{Ar}$, in etiolated tissues of many plants such as corn (Butler et al., 1963) or peas (Furuya and Hillman, 1964). This nonphotochemical change of Pfr, so called dark Pfr decay, was inhibited by metal-complexing and sulfhydryl compounds in both the tissues and cell-free system of Avena and Pisum (Furuya et al., 1965). Although the Pfr decay was prevented by respiratory inhibitors like cyanide, carbon monoxide or azide (Butler and Lane, 1965), the inhibition of Pfr decay by low $\mathrm{O}_{2}$ uptake did not necessarily imply that this process was coupled with the normal respiratory electron-transport system, or required energy, and the simplest hypothesis consistent with all the experimental facts was that the Pfr decay is a metal-dependent, probably oxidative, process (Furuya et al., 1965).

The present work is aimed at determining what kinds of metallic ions are involved in the process of Pfr decay, and in studying the effect of the ions on the mechanism of Pfr decay in Avena coleoptile tissues.

\section{Materials and Methods}

Plant material: All of the experiments in this work were carried out with etiolated oat coleoptile tissues. Seeds of Avena sativa L. cv. Zenshin obtained from Watanabe

Abbreviation: Pr, red light absor’ing form of phytochrome; Pfr, far-red light absorbing form of phytochrome; EDTA, ethylenediaminetetraacetic acid; Tris, tris(hydroxymethyl)aminomethane. 
Seed Co., Kogota, Miyagi, were presoaked in de-ionized water for $1 \mathrm{hr}$ at room temperature, then planted on water-saturated vermiculite in plastic boxes $(\mathrm{ca} .40 \times 20 \times 15 \mathrm{~cm})$. The boxes were held at ca. $25^{\circ} \mathrm{C}$ in the dark.

Test procedure: Apical $10 \mathrm{~mm}$-long coleoptile segments were cut with a WentThimann type of Avena decapitating scissors from totally etiolated 6-day-old oat seedlings under dim green light. The coleoptile segments were floated in a Tris-HCl buffer (0.05 M, pH 7.8) until all the segments needed were ready. The half of segments were incubated in the buffer containing metal complexing and/or sulfhydryl compounds for $1 \mathrm{hr}$ in the dark at $25^{\circ} \mathrm{C}$, and then washed three times by the buffer (sample D). The rest were not treated by the compounds (sample A). Lots of 20 segments of sample $\mathrm{D}$ were put into each petri dish $(6 \mathrm{~cm}$ in diameter) containing $5 \mathrm{ml}$ of the buffer with or without a known concentration of metallic compound to be tested (samples $\mathrm{B}$ and $\mathrm{C}$ respectively). Half of the lots of each sample were irradiated with red light (ca. $800 \mathrm{ergs} \mathrm{cm}^{-2} \mathrm{sec}^{-1}$ ) for $5 \mathrm{~min}$, and returned to darkness at $25^{\circ} \mathrm{C}$. The rest were kept in darkness throughout the experiments. Zero and 3 hr after irradiation, the segments were packed in a metal cuvette with an inside radius of $3 \mathrm{~mm}$ for phytochrome estimation.

Recovery rate of Pfr decay from the inhibition induced by metal complexing or sulfhydryl compounds was indicated as follows:

$$
\text { Recovery rate }(\%)=\frac{\Delta \text { Pfr in sample } \mathrm{B}-\Delta \mathrm{Pfr} \text { in sample } \mathrm{C}}{\Delta \mathrm{Pfr} \text { in sample } \mathrm{A}} \times 100
$$

where $\quad \Delta \mathrm{Pfr}=\{\Delta(\Delta \mathrm{A})$ of red irradiated samples at $0 \mathrm{hr}-$ that at $3 \mathrm{hr}\}$

$$
-\{\Delta(\Delta \mathrm{A}) \text { of dark samples at } 0 \mathrm{hr} \text { - that at } 3 \mathrm{hr}\}
$$

In most cases, the total amount of phytochrome in the red-irradiated sample at $0 \mathrm{hr}$ was equal to that in the dark control. Data were discarded in cases in which the total amount of red-irradiated samples at $0 \mathrm{hr}$ differed more than $15 \%$ of the dark control, and when the total photoreversibility of dark control lost over $20 \%$ of its initial level during the $3 \mathrm{hr}$ of incubation. In addition, rate of inhibition was shown as follows:

$$
\text { Inhibition rate }(\%)=\frac{\Delta \mathrm{Pfr} \text { in sample } \mathrm{A}-\Delta \mathrm{Pfr} \text { in sample } \mathrm{D}}{\Delta \mathrm{Pfr} \text { in sample } \mathrm{A}} \times 100
$$

Two or three replicate lots were assayed for each experimental point on at least two separate occasions.

Phytochrome assays and light sources: Phytochrome was determined with a 2 filter difference spectrophotometer (Hitachi, model 261) as already described (Pjon and Furuya, 1968). Sample cuvettes were maintained at ca. $0^{\circ} \mathrm{C}$ with crushed ice before and during the measurements. The instrument measured the optical density difference between $798 \mathrm{~nm}$ and $722 \mathrm{~nm}$. The sources of red light and green safe light were the same as described elsewhere (Pjon and Furuya, 1968). 


\section{Results}

Recovery from the inhibition of Pfr decay by metallic ions: Furuya et al. (1965) have reported that, with oat coleoptile segments, total amounts of phytochrome decreased rapidly in darkness after red irradiation in a buffer at $\mathrm{pH} 8.0$, while the amount in dark control remained more or less constant, and that $2 \mathrm{mM}$ EDTA inhibited the Pfr decay in the segments for at least $2 \mathrm{hr}$ and $0.1 \mathrm{M}$ 2-mercaptoethanol completely prevented the Pfr decay in the segments for $3 \mathrm{hr}$.

Attempts were thus made to see whether any metallic ion(s) can recover the inhibitory effects of EDTA and 2-mercaptoethanol on dark Pfr decay in oat coleoptile segments. Segments pretreated with $2 \mathrm{mM}$ EDTA and $64 \mathrm{mM}$ 2-mercaptoethanol for $1 \mathrm{hr}$ were incubated for $3 \mathrm{hr}$ in the presence of either $10 \mathrm{mM} \mathrm{AlCl}, \mathrm{CoCl}_{2}, \mathrm{CuCl}_{2}, \mathrm{FeCl}_{2}$, $\mathrm{FeCl}_{3}, \mathrm{MgCl}_{2}, \mathrm{MnCl}_{2}$ or $\mathrm{ZnCl}_{2}$ and amounts of phytochrome were measured at 0 and 3 hr. The Results are shown in Table 1.

Table 1. Effects of various metallic ions on rates of dark Pfr decay in etiolated oat coleoptile segments pretreated by $2 \mathrm{mM}$ EDTA and $64 \mathrm{mM} 2$-mercaptoethanol.

\begin{tabular}{|c|c|c|c|c|}
\hline \multirow{4}{*}{$\begin{array}{l}\text { Metallic ion } \\
\text { tested } \\
10 \mathrm{mM}\end{array}$} & \multirow{2}{*}{\multicolumn{3}{|c|}{$\frac{\text { Amount of decayed Pfr for } 3 \mathrm{hr}, \Delta(\Delta \mathrm{A}) \times 10^{4}}{\text { EDTA and 2-mercaptoethanol }}$}} & \multirow{4}{*}{$\begin{array}{c}\text { Recovery rate } \\
(\%)\end{array}$} \\
\hline & & & & \\
\hline & \multirow{2}{*}{$\begin{array}{l}\text { Not pretreated } \\
\text { (sample A) }\end{array}$} & \multicolumn{2}{|c|}{ Pretreated } & \\
\hline & & $\begin{array}{l}\text { Absence of metal } \\
\text { (sample C) }\end{array}$ & $\begin{array}{l}\text { Presence of metal } \\
(\text { sample B) }\end{array}$ & \\
\hline $\mathrm{Al}^{+++}$ & 92 & 15 & 10 & -5 \\
\hline $\mathrm{Co}^{++}$ & 103 & 12 & 9 & -3 \\
\hline $\mathrm{Cu}^{++}$ & 90 & 14 & 29 & 17 \\
\hline $\mathrm{Fe}^{++}$ & 118 & -3 & 30 & 28 \\
\hline $\mathrm{Fe}^{+++}$ & 91 & 2 & 47 & 50 \\
\hline $\mathrm{Mg}^{++}$ & 85 & 3 & 8 & 6 \\
\hline $\mathrm{Mn}^{++}$ & 100 & 0 & 16 & 16 \\
\hline $\mathrm{Zn}^{++}$ & 92 & 15 & 59 & 48 \\
\hline
\end{tabular}

It became evident that ferric and zinc ions clearly enhanced the recovery of the Pfr decay process in the segments, and that cupric, ferrous, magnesium and manganous ions were significantly less effective, whereas aluminium and cobaltous ions did not seem to release any inhibition.

Effects of ferric ion on dark Pfr decay: Dose-response curves of EDTA and $\alpha, \alpha^{\prime}-$ dipyridyl, a specific chelator to ferric ion, were quite similar as seen in Fig. 1. This fact strongly suggests that ferric ion plays an important role in dark Pfr decay in the tissue. The relationship between the degree of recovery on dark Pfr decay versus the concentration of ferric ion was then examined with oat coleoptile segments.

Recovery effect on the inhibition of Pfr decay in the presence of $2 \mathrm{mM}$ EDTA was tested at various concentrations of ferric ion with oat coleoptile segments at $25^{\circ} \mathrm{C}$. The result is presented in Fig. 2. A 50\% recovery was found to occur after incubation for $3 \mathrm{hr}$ in a solution containing ca. $1 \mathrm{mM}$ ferric ion. 


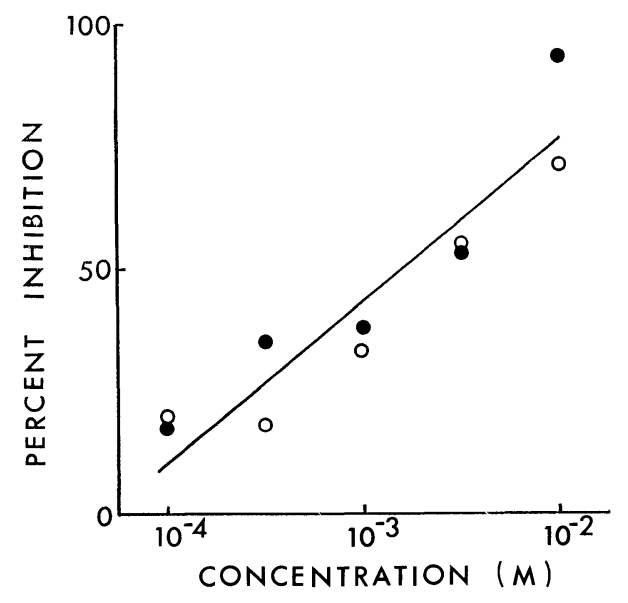

Fig. 1.

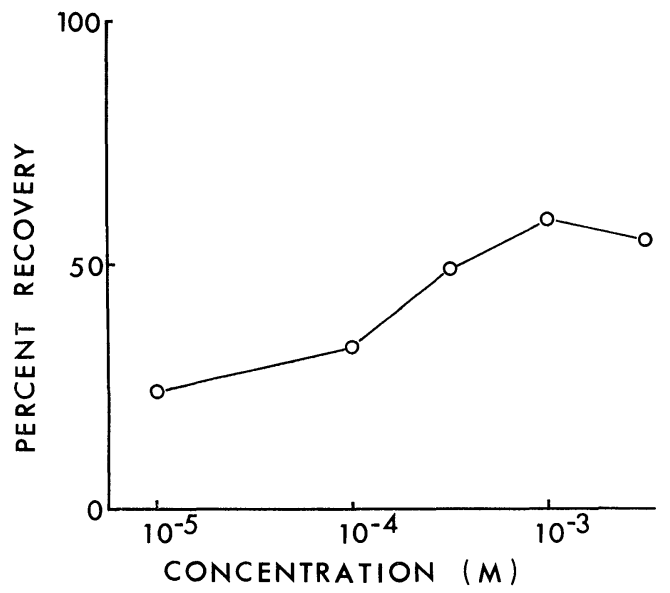

Fig. 2.

Fig. 1. Effect of EDTA (०) and $\alpha, \alpha^{\prime}$-dipyridyl $(\bullet)$ at different concentrations on the dark Pfr decay in Avena coleoptile segments at $25^{\circ} \mathrm{C}$.

Fig. 2. Effect of ferric ion at different concentrations on the recovery of Pfr decay in Avena coleoptile segments pretreated with $2 \mathrm{mM}$ EDTA.

Separation of effects by ferric and zinc ions: Similar experiments were next carried out to find whether ferric and zinc ions act the same on the EDTA- or 2mercaptoethanol-induced inhibitions of Pfr decay in oat coleoptiles. The results are summarized in Table 2. It is interesting to note that 2-mercaptoethanol-induced inhibition of Pfr decay was well recovered by the treatment with solution of zinc ion, but was much less by ferric ion. In contrast, the EDTA-induced inhibition was recovered by either ferric or zinc ion.

Table 2. Effects of ferric and zinc ions on the inhibition of Pfr decay induced by EDTA or 2-mercaptoethanol in Avena coleoptiles segments at $25^{\circ} \mathrm{C}$.

\begin{tabular}{|c|c|c|c|}
\hline \multirow{2}{*}{ Inhibitor pretreated } & \multirow{2}{*}{$\begin{array}{l}\text { Inhibition rate } \\
(\%)\end{array}$} & \multicolumn{2}{|c|}{ Recovery rate $(\%)$} \\
\hline & & $3 \mathrm{mM} \mathrm{Fe} \mathrm{Fe}^{+++}$ & $3 \mathrm{mM} \mathrm{Zn}^{++}$ \\
\hline EDTA, $2 \mathrm{mM}$ & 74 & 53 & 41 \\
\hline 2-mercaptoethanol, $50 \mathrm{mM}$ & 78 & 18 & 39 \\
\hline
\end{tabular}

A relationship between concentrations of diethyldithiocarbamate, a specific chelator to cuprous and zinc ions, and the degree of inhibition of Pfr decay was determined with oat coleoptile segments at $25^{\circ} \mathrm{C}$. The results in Fig. 3 shows that $50 \%$ inhibition of Pfr decay occurred at ca. $10^{-3} \mathrm{M}$ of diethyldithiocarbamate and the process was almost completely prevented at $10^{-2} \mathrm{M}$.

Recovery effect on the inhibition induced by $50 \mathrm{mM}$ 2-mercaptoethanol and 2 mM EDTA was examined with incubation for $3 \mathrm{hr}$ in zinc ion at various concentrations (Fig. 4). The 50\% recovery in so treated segments was observed at ca. $10^{-2} \mathrm{M}$ zinc ion. 


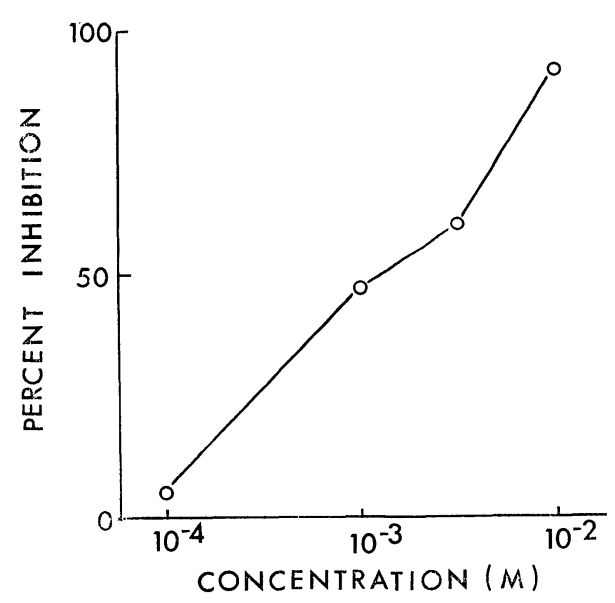

Fig. 3.

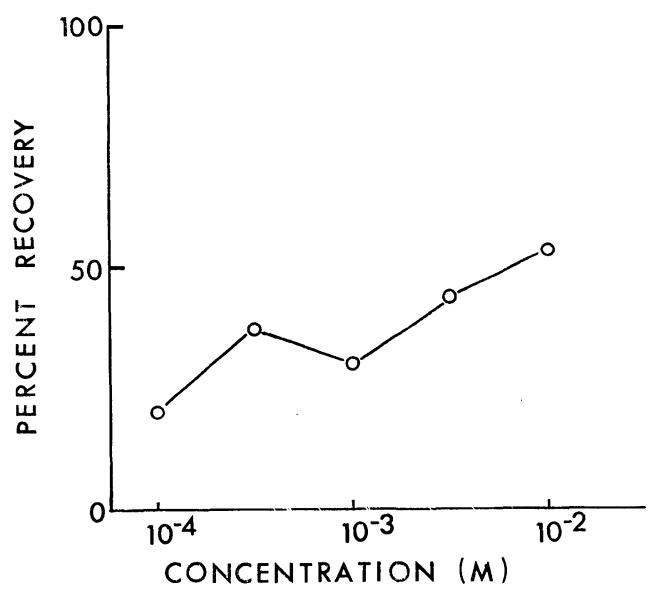

Fig. 4.

Fig. 3. Effect of diethyldithiocarbamate at different concentrations on the dark Pfr decay in Avena coleoptile segments at $25^{\circ} \mathrm{C}$.

Fig. 4. Effect of zinc ion on recovery of Pfr decay in oat coleoptile segments pretreated with 0.05 M 2-mercaptoethanol and $2 \mathrm{mM}$ EDTA.

Lack of effect of metallic ions on the inhibition of dark Pfr decay induced by respiratory inhibitors: Butler and Lane (1965) have already reported that respiratory inhibitors such as azide or carbon monoxide prevented the process of dark Pfr decay in corn coleoptiles. In our study, the effects of antimycin $A$ and rotenone on dark Pfr decay were determined with oat coleoptile segments. As shown in Fig. 5, antimycin A which is known as an inhibitor upon components in region II of the electron transfer system (Racker, 1965) was several hundreds times more effective in terms of $50 \%$ inhibition level than rotenone, an inhibitor on components in region I of the electron transfer system. It was thus confirmed that, when the electron transfer system of terminal oxidation was prevented by the inhibitors, the process of Pfr decay always stopped in the plant tissue.

Finally, an attempt was made to see whether the addition of metallic ions to tissues can nullify the inhibition of Pfr decay by respiratory inhibitors, as found with effects of EDTA or 2-mercaptoethanol. The result is presented in Table 3. It is clear 
Table 3. Effects of ferric or zinc ions on azide-induced inhibition of Pfr decay in oat coleoptile segments.

\begin{tabular}{c|c|c|c}
\hline \hline \multirow{2}{*}{ Inhibitor pretreated } & $\begin{array}{c}\text { Inhibition rate } \\
(\%)\end{array}$ & \multicolumn{2}{|c}{ Recovery rate (\%) } \\
\cline { 2 - 4 } & $3 \mathrm{mM} \mathrm{Fe}{ }^{+++}$ & $3 \mathrm{mM} \mathrm{Zn}^{++}$ \\
\hline Azide, $2 \mathrm{mM}$ & 89 & 14 & 19 \\
\hline
\end{tabular}

that little recovery effect of metallic ions was observed with the respiratory inhibitorinduced inhibition of Pfr decay.

\section{Discussion}

The results in the present work not only strongly support the hypothesis proposed in the previous paper (Furuya et al., 1965) that Pfr decay in vivo, whether it is enzymatic or nonenzymatic, depends on the activity of a metal, but also it becomes evident that metal-complexing reagents like EDTA or $\alpha, \alpha^{\prime}$-dipyridyl acted to prevent a process which is different from a sulfhydryl compound-sensitive site. Since it is reasonable to suppose that the in vivo Pfr decay may be related to the biochemical role of phytochrome, the separation of dark Pfr decay into two metal-dependent processes is certainly important to analyse the mechanism of plant photomorphogenesis.

Since metallic ions tested in the present work (Table 1) show more or less similar stability constants of metal-ion complexes with EDTA, recovery effects of ferric and zinc ion are not reults of non-specific cancellation of the chelating effect, but rather that there are sites in the dark decay system which specifically depend on ferric and zinc ions.

Butler et al. (1965) reported that dark decay of phytochrome had been inhibited by inhibitors of respiration, such as azide, cyanide and so on. The result in Table 3 shows that the inhibition of azide was little recovered by ferric and zinc ions. This fact suggests that the respiration-dependent step(s) of the dark decay process is different from those site(s) of ferric and zinc ion dependence. The data in this work thus seems to show that the process of dark decay consists of at least three steps. The facts that antimycin A strongly inhibited the process and rotenone was less inhibitory suggest that only a part of respiratory chain couples with dark Pfr decay.

In addition, Manabe and Furuya (1971) recently reported that Pfr decay was not seen during any purification step at an alkaline $\mathrm{pH}$ with solutions obtained from etiolated pea epicotyl, but it occurred in the acidic range of $\mathrm{pH}$ even in the presence of sulfhydryl compounds. Apparently the process of Pfr decay is controlled by many factors, only some of which may be suggested by the above findings.

\section{References}

Butler, W.L. AND H.C. Lane. 1965. Dark transformations of phytochrome in vivo. Plant Physiol. 40: 13-17.

H.C. Lane and H.W. Siegelman. 1963. Nonphotochemical transformations of phytochrome in vivo. Plant Physiol. 38: 514-519. 
Furuya, M. AND W.S. HILlman. 1964. Observations on spectrophotometrically assayable phytochrome in vivo in etiolated Pisum seedlings. Planta 63: 31-42.

, W.G. Hopkins AND W.S. Hillman. 1965. Effects of metal-complexing and sulfhydryl compounds on nonphotochemical phytochrome changes in vivo. Arch. Biochem. Biophys. 112: 180-186.

Manabe, K. And M. Furuya. 1971. Factors controlling rates of nonphotochemical transformation of Pisum phytochrome in vivo. Plant Cell Physiol. 12: 95-101.

PJon, C.J. AND M. FuruYa. 1968. Phytochrome action in Oryza sativa L. II. The spectrophotometric versus the physiological status of phytochrome in coleoptiles. Planta 81: 303-313.

RaCker, E. 1965. Mechanisms in bioenergetics. Academic Press Inc., New York.

Received November 15, $19 \% 1$ 